Avaiable online at www.banglajol.info

Bangladesh J. Sci. Ind. Res. 43(4), 537-544, 2008

BCSIR

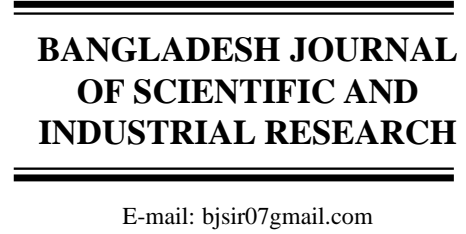

E-mail: bjsir07gmail.com

\title{
Effect of Particle Size of Quartz on Bending Strength of Porcelain
}

\author{
Sonjida Mustafi, Mainul Ahsan* and A.H. Dewan \\ Institute of Glass \& Ceramic Research and Testing (IGCRT), Bangladesh Council of \\ Scientific \& Industrial Research (BCSIR), Dhanmondi, Dhaka-1205, Bangladesh.
}

\begin{abstract}
The bending strength of porcelain body has been experimentally studied because of its economic importance in ceramic industry. The maximum bending strength is obtained in the $<44 \mu$ particle sized quartz containing porcelain at $1300^{\circ} \mathrm{C}$. The distribution of closed pores, their geometric shapes and possible link with each other control the bending strength of the ceramic body. The presence of unmelted fine quartz grains in the ceramic body also increases the bending strength. It has been found that the bending strength increases with increasing bulk density of the ceramic bodies and the firing temperature up to $1300^{\circ} \mathrm{C}$, but at temperature above $1300^{\circ} \mathrm{C}$, the bending strength decreases due to bloating of isolated pores and the disappearance of quartz, which are also associated with a decrease in bulk density. The purpose of this study is to investigate on the differential changes of bending strength of porcelain bodies upon using quartz of various grain sizes at different firing temperatures.
\end{abstract}

Key Words : Particle size, Quartz, Bending strength, Firing temperature and bulk density.

\section{Introduction}

Quartz grains in different sizes have significant effect on mechanical strength of porcelain bodies (Hamano et.al.,1991). Especially, it is proposed that bending strength of porcelain increases with an increase in the inter planer spacing of quartz crystals, so the quartz is under the tensile stress, and consequently, the glassy matrix surrounding the quartz grains is in a compressive stress, (acting as pre-stress) improving mechanical strength (Hamabo, et.al.,1992). It is also reported that with respect to the amount of quartz content of bodies, the pre-stress effect increases with an increase in the amount of residual quartz in bodies (Mattyasovszky, 1957). There are some other scientific arguments about the effects of quartz grains on mechanical strength of porcelain. It has been experimentally documented that the presence of higher amount of fine grained quartz

*Author for correspondence 
increases the strength (Wiedmann,1959). In contrast, other studies claim that a low quartz content provides high strength (Weyl, et.al.1959 ; Palatzky, et.al.,1958). The objective of this study is to investigate on the variation of bending strength of porcelain bodies at various grain size of quartz and at different firing temperatures.

\section{Materials and Methods}

Size separation of quartz and feldspar grains was carried out by sieve analysis after pulverizing the samples. Quartz and feldspar grains were dried in an oven. The particle size of quartz are $<44 \mu$ (series1), $44-66 \mu$ (series2) and $66-76 \mu$ (series3) respectively and feldspar is $<76 \mu$. Standard composition of ceramic bodies was prepared on mixing Bijoypur clay (50wt\%),

K-feldspar (25wt\%) and fine quartz (25wt\%). Table I shows the results of the chemical analysis of the raw materials. Three groups of sample were prepared, each mixture was ground gently and then mixed with distilled water while stirring and then dried in air. Then the mixtures were ground gently again in order to obtain the best mixing. To avoid lamination problem occurring during the pressing of samples, each powder mixture was moistened with ethanol. Test pieces were prepared by mould under a pressure of 6 tons. Samples were kept at ambient temperature for $48 \mathrm{~h}$. for the evaporation of ethanol. The compacted samples were placed in an electric furnace, heated at rate of $5^{\circ} \mathrm{C} / \mathrm{min}$ and fired at $1200^{\circ} \mathrm{C}, 1250^{\circ} \mathrm{C}$, $1300^{\circ} \mathrm{C}, 1350^{\circ} \mathrm{C}$ and $1400^{\circ} \mathrm{C}$ for $1 \mathrm{~h}$ and then cooled in the furnace.

The bending strength was measured by a Universal Testing Machine (Shimadzu UTM Model Autograph AGS-10 KNG) on 15 tests pieces for each body by a three-point loading test. The various physical properties such as bulk density (BD), apparent porosity (AP) and water absorption (WA) of the specimens were determined by Archimedes's immersion technique on keeping the specimens in boiling water for $2 \mathrm{~h}$.

\section{Results and Discussion}

\section{Bulk density}

Fig.1 clearly displays differential changes in bulk density with the firing temperature.

Table I. Chemical composition of raw materials

\begin{tabular}{l|c|c|c|c|c|c|c|c|c}
\hline $\begin{array}{l}\text { Raw } \\
\text { materials }\end{array}$ & $\begin{array}{c}\mathrm{SiO}_{2} \\
(\%)\end{array}$ & $\begin{array}{c}\mathrm{Al}_{2} \mathrm{O}_{3} \\
(\%)\end{array}$ & $\begin{array}{c}\mathrm{Fe}_{2} \mathrm{O}_{3} \\
(\%)\end{array}$ & $\begin{array}{c}\mathrm{CaO} \\
(\%)\end{array}$ & $\begin{array}{c}\mathrm{MgO} \\
(\%)\end{array}$ & $\begin{array}{c}\mathrm{K}_{2} \mathrm{O} \\
(\%)\end{array}$ & $\begin{array}{c}\mathrm{Na}_{2} \mathrm{O} \\
(\%)\end{array}$ & $\begin{array}{c}\mathrm{TiO}_{2} \\
(\%)\end{array}$ & $\begin{array}{c}\text { Loss on } \\
\text { ignition } \\
(\%)\end{array}$ \\
\hline Bijoypur clay & 53.55 & 28.17 & 1.55 & 0.071 & 0.161 & 0.705 & -- & 1.58 & 14.10 \\
Feldspar & 65.09 & 18.38 & 0.067 & 0.146 & -- & 13.67 & 1.57 & -- & 0.57 \\
Quartz & 98.29 & 0.296 & 0.054 & -- & 0.621 & 0.042 & -- & -- & 0.70 \\
\hline
\end{tabular}




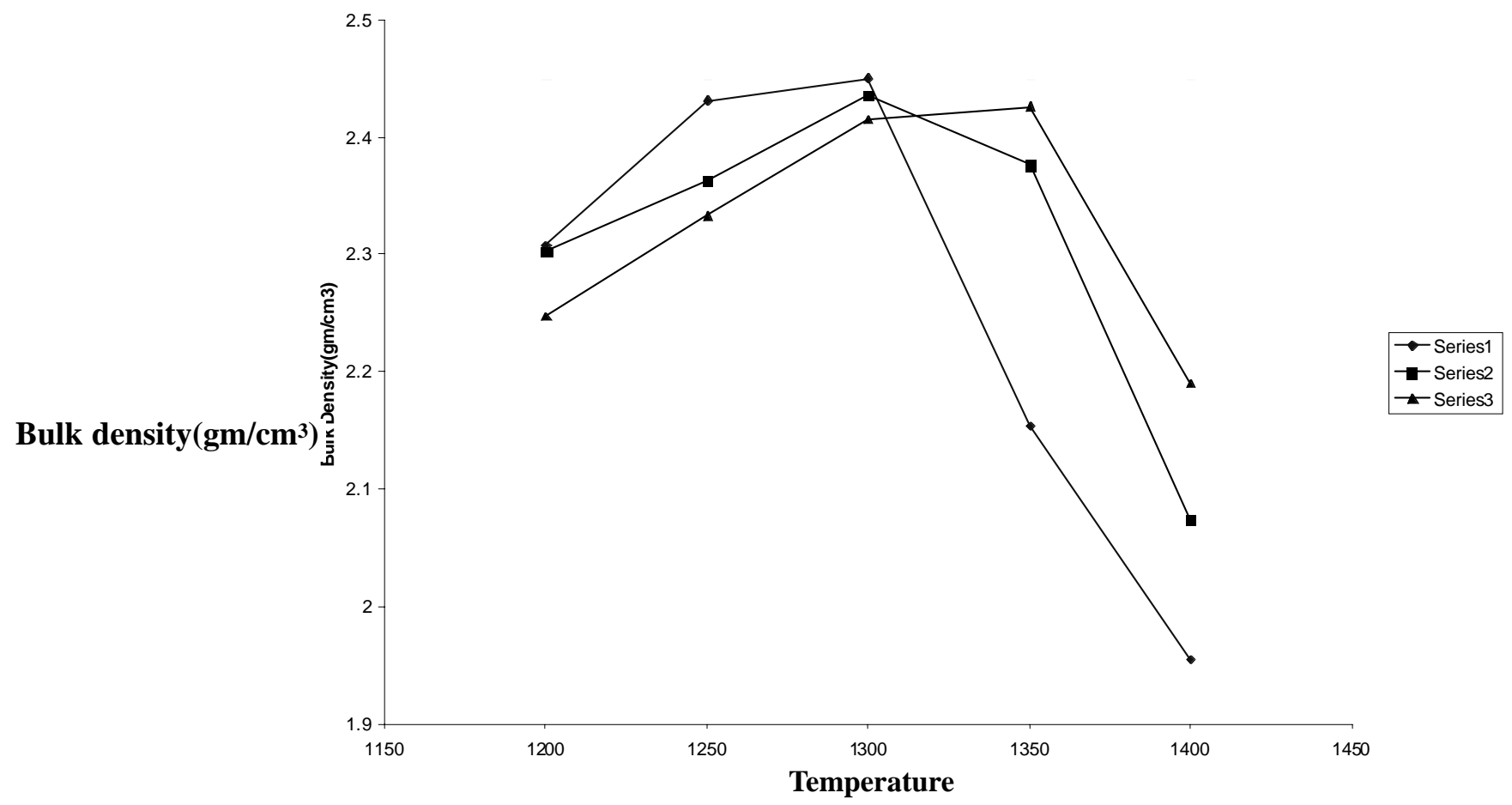

Fig-1. Effect of firing temperature on bulk density as a function of grain size of quartz.

With increasing firing temperature the bulk density passes through a maximum value as observed in almost all porcelain bodies (Mattyasovszky, 1957). At higher firing temperature, the porcelain containing the finer sized quartz grains should have higher bulk density. At $1300^{\circ} \mathrm{C}$, density is the highest for the material containing $<44 \mu$ sized quartz grains and above $1350^{\circ} \mathrm{C}$, density is lower. Similarly, above $1350^{\circ} \mathrm{C}$, the bulk density decreases for materials containing quartz grain sizes of $44-66 \mu$ and $66-76 \mu$ due to more porosity developments. At higher temperatures, the closed porosity tends to increase because of bloating and consequently the bulk density decreases rapidly. The source of "bloating" could be $\mathrm{O}_{2}$ released from the reaction of $\mathrm{Fe}_{2} \mathrm{O}_{3}$ to $\mathrm{Fe}_{3} \mathrm{O}_{4}$ (Soma, et.al.,1980). As a result $<44 \mu$ sized quartz grains containing porcelain is reached to a high bulk density at a lower sintering temperature. In contrast $66-76 \mu$ sized quartz grains containing porcelain has a higher sintering temperature and higher bulk density than the other porcelains, because of the formation of a more homogeneous vitreous matrix

\section{Apparent porosity}

Porosity affects the strength of the ceramic body. Porous porcelain is mechanically 


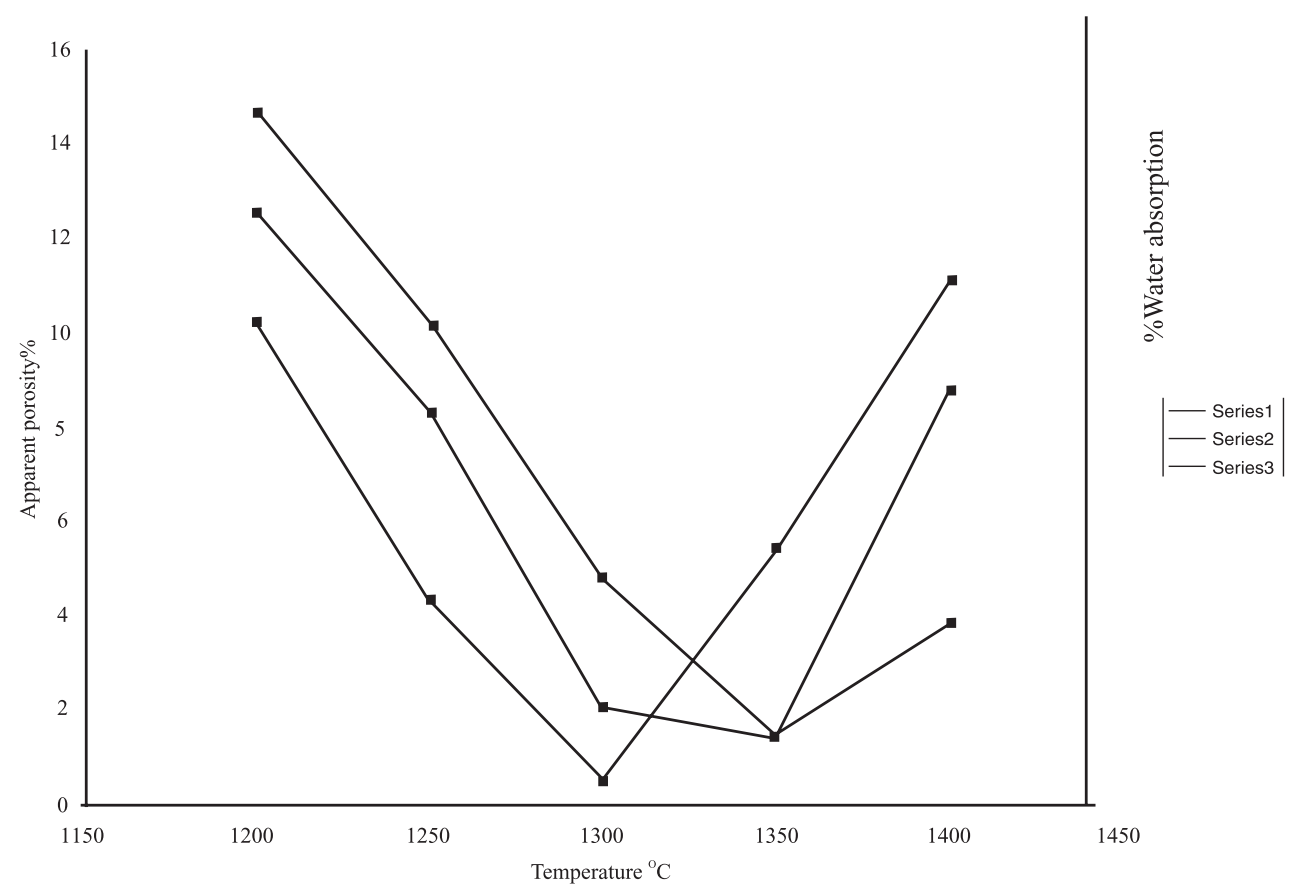

Fig : 2. Effect of firing temperature on apparent porosity as a function of grain size of quartz.

weak. Lower porosity gives greater strength.

Fig.2 shows differential changes of apparent porosity with the quartz grain size and the firing temperature. The apparent porosity continues to decrease with temperature, reaches a minimum value, and then increased. At $1300^{\circ} \mathrm{C}$, the porcelain containing $<44 \mu$ sized quartz grains has the lowest apparent porosity $(0.55 \%)$. The apparent porosity is lower for $<44 \mu$ sized quartz grain containing product than other two at above $1300^{\circ} \mathrm{C}$. However the apparent porosity is decreased with increasing the size of quartz grains used to make products. Water absorption is proportional to porosity and so water absorption imparts the same effect on bending strength as does porosity.

\section{Bending strength}

It is observed from the Fig. 3 the bending strength of porcelain body is increased with decreasing quartz grain size and reached maximum value $76.8 \mathrm{MPa}$ in fine $<44 \mu$ quartz grain containing ceramic body. The bending strength of quartz grain sized 44$66 \mu$ and $66-76 \mu$ are $44.41 \mathrm{MPa}$ and 41.23 $\mathrm{MPa}$ respectively which are lower than the quartz grain sized $<44 \mu$.

Fig.4 shows the variations of bending strength with the firing temperature $\left(1200^{\circ} \mathrm{C}\right.$ - $1400^{\circ} \mathrm{C}$ ). The bending strength of ceramic bodies is increased with an increase in firing temperature and reached maximum value of 


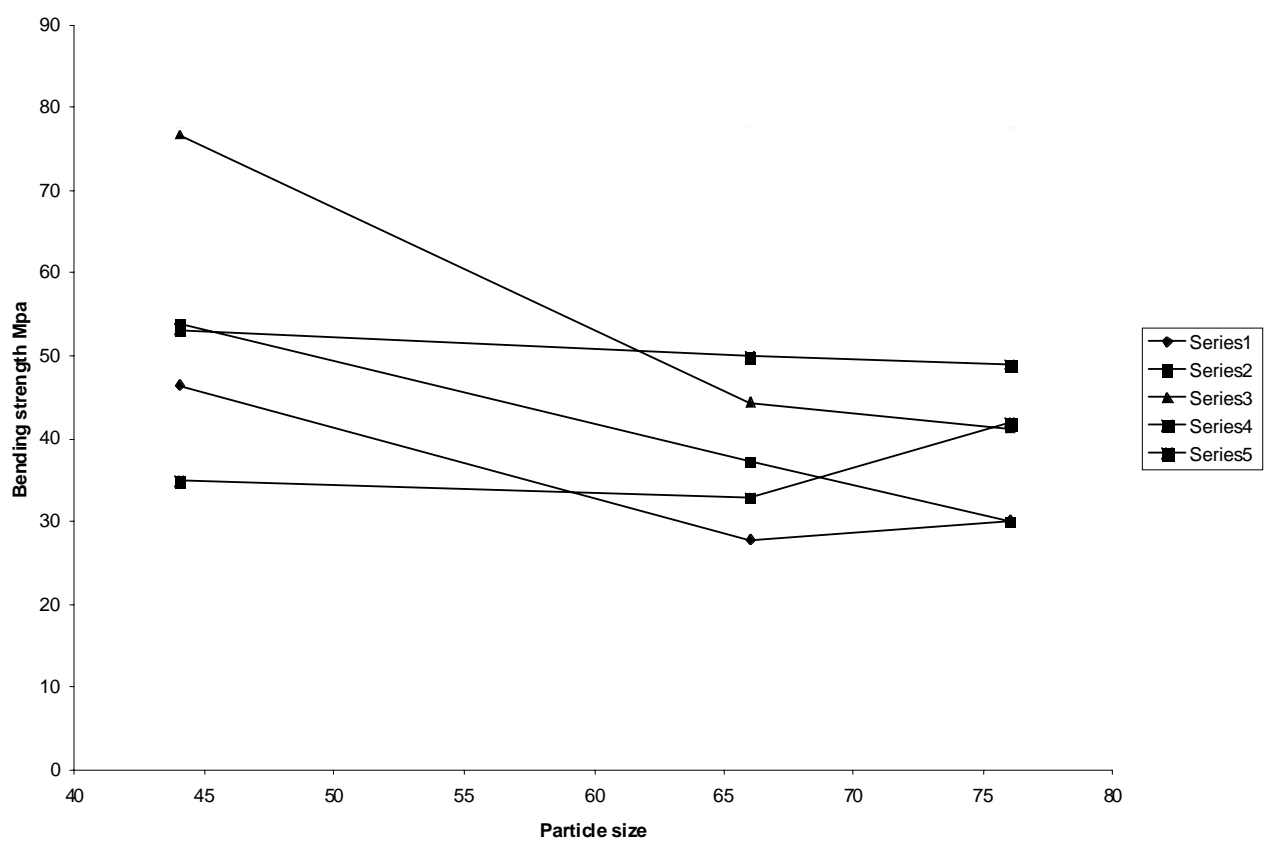

Fig.3. Bending strength of fired body vs grain size of quartz.

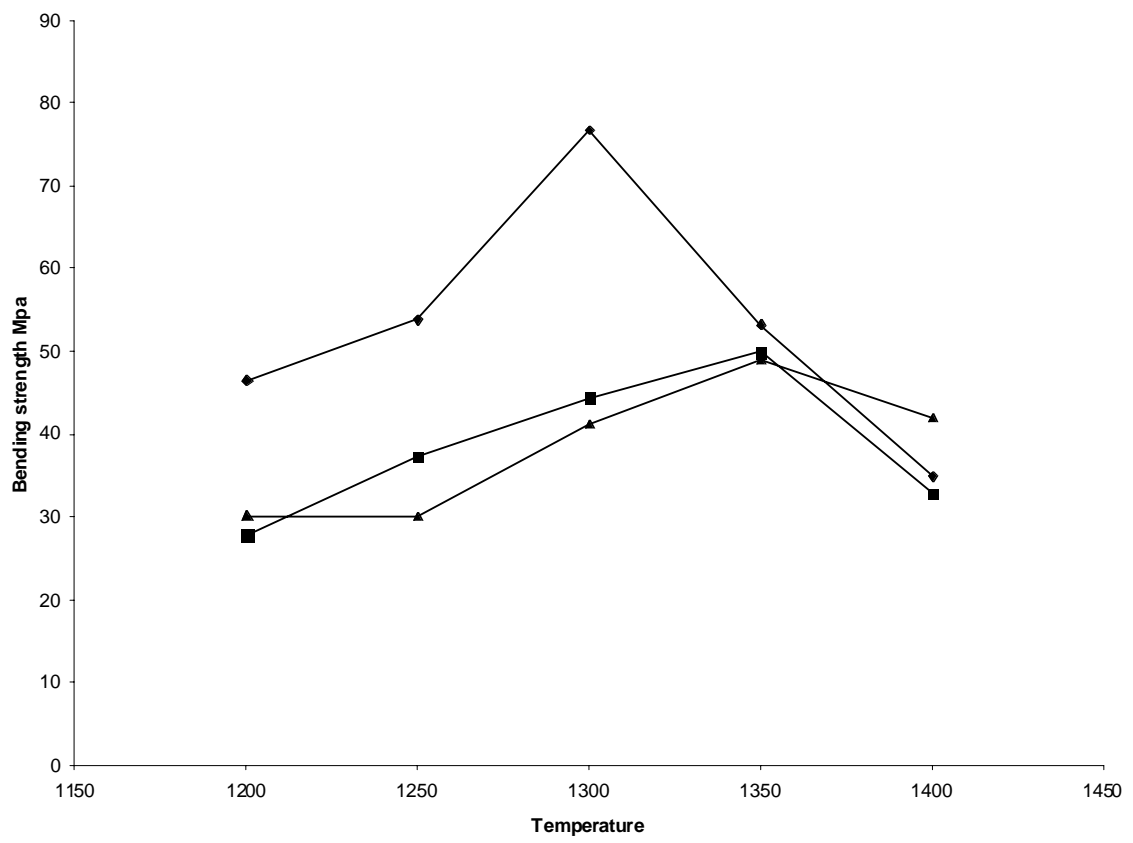

Fig-4. Effect of firing temperature on bending strength as a function of grain size of quartz. 
76.8 $\mathrm{MPa}$ at $1300^{\circ} \mathrm{C}$ in fine $<44 \mu$ quartz grain containing ceramic body. On further heating, the bending strength is decreased due to microstructural changes, causing more porosity developments. At the higher firing temperature, the bending strength should be attained. However quartz grain sizes decrease as firing temperature continues to increase after reaching the maximum temperature, the bending strength begins to

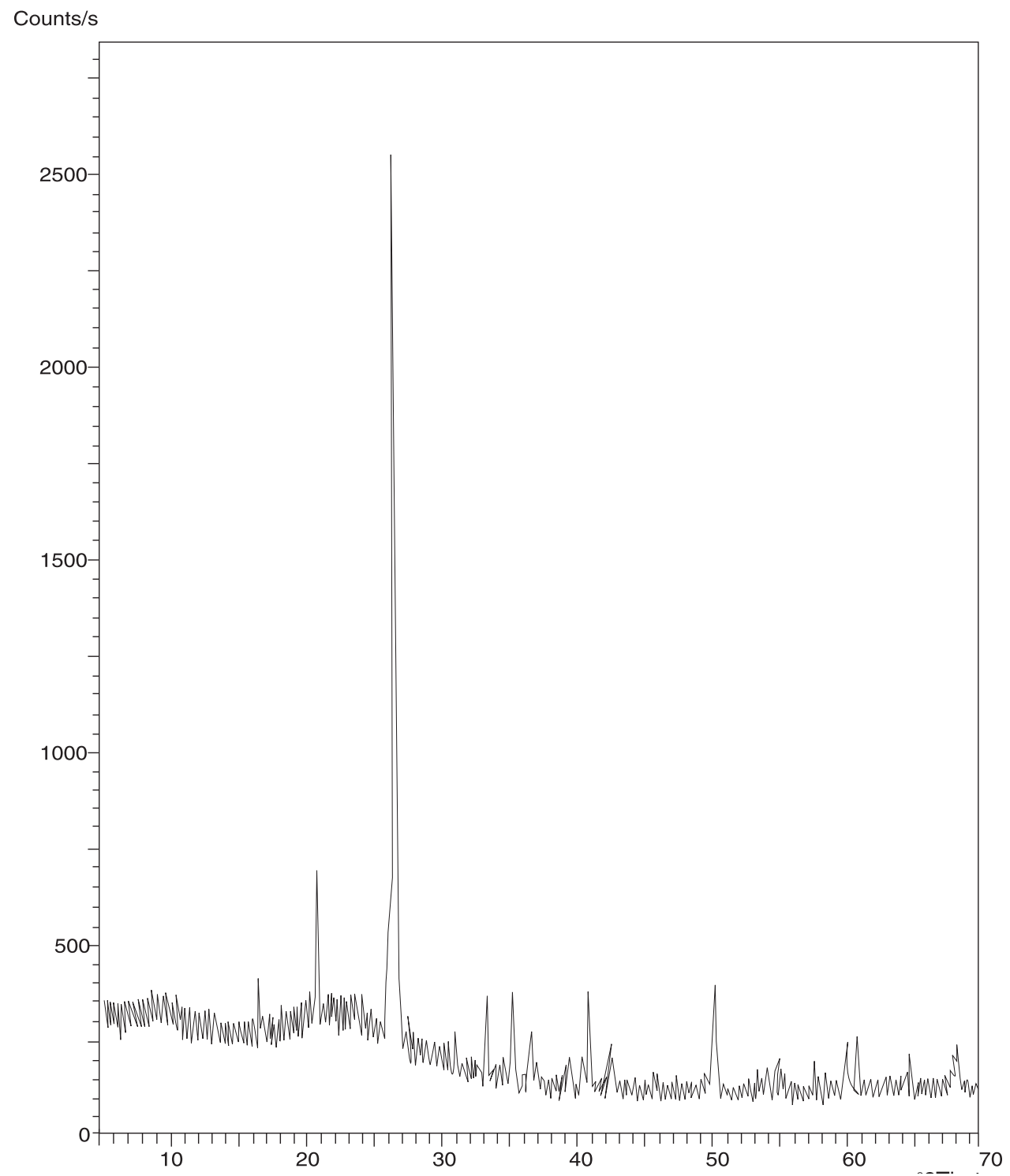

Fig.5 XRD pattern of $<44 \mu$ particle size quartz at $1400^{\circ} \mathrm{C}$. 
decrease together with a decrease in bulk density due to close porosity development.

It is observed that the bending strength of $<44 \mu$ sized quartz grains containing porcelain body is tended to behave differently from other porcelain group 44-66 $\mu$ and 66$76 \mu$ quartz grain size. It is started from 46.4 $\mathrm{MPa}$ at $1200^{\circ} \mathrm{C}$ which is increased to its maximum value at $1300^{\circ} \mathrm{C}$ and then gradually decreased down to $34.9 \mathrm{MPa}$ at $1400^{\circ} \mathrm{C}$ which is lower than the starting value at $1200^{\circ} \mathrm{C}$. The sintering and bending strength behaviors of $44-66 \mu$ and $66-76 \mu$ quartz grain size containing porcelain bodies are differed from those of $<44 \mu$ quartz grain size containing porcelain. The bending strength of $<44 \mu$ quartz grain size containing porcelain at $1200^{\circ} \mathrm{C}$ is higher than the other two porcelain body. It is obvious that these changes in bending strength are related to total porosity developments in body.

The bending strength of $44-66 \mu$ quartz grain size containing porcelain at $1200^{\circ} \mathrm{C}$ is 27.8 $\mathrm{MPa}$ which is the lowest bending strength from other two bending strength $46.44 \mathrm{MPa}$ and 30.16 MPa of quartz grain size $<44 \mu$ and $66-76 \mu$ respectively. It is increased rapidly with an increasing in firing temperature from $1200^{\circ} \mathrm{C}$ to $1350^{\circ} \mathrm{C}$. After reaching the maximum bending strength of $49.9 \mathrm{MPa}$ at $1350^{\circ} \mathrm{C}$, it is almost stay on the same level of strength up to $1350^{\circ} \mathrm{C}$, and then decreases rapidly on further heating.
The phase changes in porcelain bodies are investigated by using X-ray diffraction analysis. Fig. 5 shows the XRD pattern of $<44 \mu$ particle size quartz at $1400^{\circ} \mathrm{C}$. The strength is increased with mullite $\left(3 \mathrm{Al}_{2} \mathrm{O}_{3} \cdot 2 \mathrm{SiO}_{2}\right)$ content which is affected by quartz grain size and firing temperature upto about $<44 \mu$ size limit, after that larger quartz grains have an inverse effect on the mullite content and the strength.

\section{Conclusion}

The following conclusions have been drawn:

1. The bending strength is dependent on the particles size of Quartz.

2. The porcelain above the optimum sintering temperature would loss its strength.

3. The bulk density passes through a maximum value with rise of sintering temperature as expected.

4. The sintering temperature of porcelain bodies was dependent on the particles size of the raw materials.

\section{References}

Hamano, K. Wu, Y. H. Nakagawa, Z. Hasegawa, M. (1991) Effect of grain size of quartz on mechanical strength of Porcelain body. $J$. Ceram. Soc. Jpn 99: 149-153. 
Hamano, K. Nakagawa, Z. Hasegawa, M. (1992) Improvement of mechanical strength of porcelain bodies by fine grinding of raw materials. J. Ceram. Soc. Jpn 100: 1051 1054.

Mattyasovszky-zsolvay, L. (1957) Mechanical strength of porcelain. J. Am. Ceram. Soc. 40: 299-306. Wiedmann, T. Sprech 92(1959)2-5.
Palatzky, A. Tummler, W. Silikattechnik (1958) Bending Strength of Porcelain 9: 68-73.

Soma, T. Matsui, M. Oda, I. Yamamoto, N. (1980) Applicability of crack propagation data to failure prediction in porcelain. $J$. Am. Ceram. Soc. 63: No.3-4: 166-169.

Weyl, D. Deut, Berichte. (1959) Keram. Ges. 36:319-324.

Received : March 13, 2008;

Accepted : June 29, 2008 